\section{Best Practice in Europe}

The Committee of Experts on the impact of new technologies on the quality of the life of persons with disabilities (P-RR-NTH) of the Council of Europe collected data from the member states of the Partial Agreement in the Social and Public Health Field of the Council of Europe, from European International NonGovernmental Organisations and from other organisations in various ways over a period stretching from mid 1998 to the beginning of $2001^{1}$. Information on the impact of new technologies on the quality of life has been analysed. The conclusions summarise the Best Practice to improve quality of life for older persons and persons with disabilities. In the end a Best Practice Country is chosen.

\section{Education}

Accepted policy on education is mainstreaming of education for all pupils if possible. This requires accessibility of transport, buildings, educational hardware and software. There is a strong need for early implementation of new technologies in education. Accessible infrastructures but also assistive technology enable education for pupils with severe disabilities. New technologies offer specific possibilities for the target group as well as for the teacher.

\section{Vocational guidance and training}

Accepted policy is also here mainstreaming vocational guidance and training for all students if possible. This requires accessibility of transport, buildings, hardware and software in normal vocational training. ICT offers a wide range of systems, alternative methods and supporting services to enable training and guidance for students with disabilities as well as staff.

\section{Employment}

New technology is a danger for many traditional jobs. However, new technologies can support (re)integration of persons with disabilities in normal jobs as it contributes essentially to the proper outfitting and adaptation of workplaces, working conditions and geographical work environments. New tech- nologies, especially ICT, also contribute to the adaptation of workplaces for persons with mental disabilities.

\section{Social Integration and Environment}

Consumer technology based on design-forall principles, produced along modern production lines, contributes to the independence and integration in society. The market needs stimulation to move towards a normal consumer market with consumer products based on the principles of design for all. Specific sub groups with related problems, like older people and persons with disabilities, join the market to form a larger front. As a result of the use of new technologies, the prospects of creating an accessible built environment are closer at hand than before. Stimulating legislative measures, standardisation, education and perhaps, first of all, continuing awareness creation are cornerstones in reaches success.

\section{Training of persons involved in} rehabilitation and social integration

Considering the importance of (new) technologies for persons with disabilities, a condition sine qua non is that professionals in all areas are aware of the possibilities and have the appropriate knowledge and understanding of what technology can do. Additional training of professionals and others involved in all dimensions of technology is needed.

\section{Research and development}

'Design-for-all' as a principle is first and foremost an ethical approach and is never fully attainable. Therefore the 'design-for-all' approach needs to be accompanied by an additional policy on assistive technology resulting in the completion of the potential of new technologies for all persons with disabilities. All parties should be involved, including end users and industry, in research and development of design-for-all products.

\section{Standardisation}

Guidelines on 'design-for-all' are a ground for future product directives and standardis-

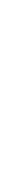


ation at international level, important for design and testing. The recent initiative from ANEC with ISO and CEN "Guideline for a more accessible world" is a good starting point for future actions. The example of the standardisation in the USA, being impact of legislation (ADA), shows what standardisation can achieve.

\section{User involvement}

User involvement is increasing but not at all common use in all processes. Users create awareness of their specific, but also their general problems, enable proper steering and selection of processes and measures. Users have to be educated more and given assistance in participation.

\section{Service Delivery}

Persons with disabilities but also professionals need support and guidance in solving problems, identify possible solutions and enable solving. A coherent framework for service delivery is necessary.

\section{Awareness creation}

National plans for increasing awareness on the impact of new technologies in the quality of life for persons with disabilities should be exchanged between the member states. Attention must be given to how ICT accessibility can be an appropriate goal of public procurement. Better awareness of the implications of the design-for-all approach, could create market competitiveness and stimulate research and development.

\section{And the winner is.....}

National Reports were viewed of Austria, Belgium, Cyprus, Denmark, Finland, Germany, Hungary, Ireland, Italy, Latvia, Luxembourg, Netherlands, Norway, Portugal, Slovenia, Spain, Sweden, and the United Kingdom. Best Practice was reported from Germany and Norway.

\section{Reference}

1. Bougie T. 2001 (May). The Impact of New Technologies on the Quality of Life of Persons with Disabilities. Consultancy Report to the Committee of experts on the impact of new technologies on the quality of life of persons with disabilities. Report P-SG (99)

35.5, Council of Europe, Strasbourg

Theo Bougie MSc, Hoensbroek, Netherlands, e-mail: theo.bougie@tref.nl

\section{In Memoriam Sir John Harington of Kelston (1561-1612)}

At the end of the $16^{\text {th }}$ Century Sir John Harington of Kelston (Somerset, England) reinvented a 'washout' closet. It had already been installed in the Minoan Palace of Knossos in $1700 \mathrm{BC}$ but the technology was lost for thousands of years. Harington constructed this piece of technology to serve an old lady, Queen Elizabeth I of England (15331603), then aged 61 years, making this toilet a genuine piece of gerontechnology. It was a portable toilet shaped like a box covered with red velvet and trimmed in lace with a lid and carrying handles. The technology itself was fairly cheep. It cost only 6 shillings and 8 pence but the idea did not catch on until two centuries later when drainage systems were installed in major cities. In 1778 Joseph Bramah, a British cabinetmaker, patented the flush toilet. Sir John never received any benefit from his invention.

Harington had been educated at Eton, Cambridge, and Lincoln's Inn, London and became a poet, translator, writer, and courtier, who won a knighthood in 1599 on a military expedition to Ireland. His father had first married an illegitimate daughter of the English king Henry VIII. His father's second wife, and mother of John Harington, was an attendant to the Princess Elizabeth, who stood as godmother for the young John.

The high-spirited Harington had easy natural wit. He was a fine poet. In his mid-twenties 